Egypt. Acad. J. biolog. Sci., 1(1): 57-64 (2009)

Email: egyptianacademic@yahoo.com

Received: 10/11/2009
C. Physiology \& Molecular Biology

ISSN: 2090-0767

www.eajbs.eg.net

\title{
Universal Primer for Early and Rapid Detection of Nucleopolyhedroviruses of Multiple Species Using Polymerase Chain Reaction
}

\author{
Fatma H. Galal \\ Dept of Entomology, Fac of Science, Cairo Univ, Giza, Egypt, 12211.
}

\begin{abstract}
A technique using the polymerase chain reaction (PCR) was developed for detection of the nucleopolyhedrovirus (NPV) polyhedrin gene. 152 nucleotide sequences of polyhedrin gene were compared in pairwise and multiple alignment sequences. Eleven highly conserved DNA sequences within the coding region of the polyhedrin gene were identified. Two candidate regions were targeted for amplification and consequently one pair of degenerate PCR primers was designed to produce fragments of about $355 \mathrm{bp}$. The NPVs tested by this technique were Autographa californica (AcMNPV), Bombyx mori NPV (BmNPV), Hyphantria cunea NPV (HcNPV), Lymantria dispar NPV (LdNPV), Spodoptera exigua NPV (SeNPV), S. litura NPV (SINPV), Spodoptera littoralis NPV (SpliNPV) and nine local NPV isolates. Furthermore, three randomly chosen PCR products were cloned and sequenced. The sequencing data showed that the three PCR products were fragments of polyhedrin gene. Conclusively, this technique would be useful in monitoring the environmental fate, distribution of NPVs, release of the wild type and recombinant NPVs and quality control studies of baculoviral insecticides as well.
\end{abstract}

Keywords: Nucleopolyhedroviruses, baculovirus, PCR, polyhedrin gene

\section{INTRODUCTIION}

Baculoviruses have a large circular double-stranded DNA genome ranging from approximately 80 to 180 $\mathrm{kb}$ in size (Blissard and Rohrmann, 1990). They are considered to be the largest and most broadly studied insect viruses because they are of great interest and utility to large cross-sections of agricultural and biomedical research community. They have been thoroughly investigated due to its potential as insect control agent (Wood and Robert, 1991), and as a vector expressing various heterologous genes (Summers and Smith, 1987, Choi et al., 1999). Although Murphy et al. (1995) have reported baculovirus infections in over 600 insect species in the order of Lepidoptera, Hymenoptera, Diptera, Coleoptera, Neuroptera, Trichopera and Thysanura, as well as in the Crustaceae order Decapoda (shrimps), it is recently confirmed that only those derived from orders Lepidoptera, Hymenoptera, and Diptera are members of the family Baculoviridae (ICTV, 2009). Those from Orthoptera were classified as pox viruses, isolates from Coleoptera are so far not assigned (ICTV, 2009). Neuropterans were infected under laboratory conditions and larval death from the virus infection was not documented. Shrimp viruses have now been classified as Nimaviridae in the genus Whispovirus and are no longer baculoviruses (Marks et al., 2005). The commercialization and release of recombinant viruses in the environment created the concern that they might cause ecological disturbances, such as displacement of native microorganisms, adverse effects on non-target organisms and the horizontal transfer of DNA into non-target organisms (Leung et al., 1994). For the above mentioned reasons, many authors were interested in developing an accurate and easy 
diagnostic method for early and rapid detection of NPV infections (Wang et al., 2000, Christian et al., 2001, Moraes and Maruniak, 2001, Woo, 2001, Lange et al., 2004, Jehle et al., 2006, Murillo et al., 2006).

Several methods have been employed to detect wild type or recombinant nucleopolyhedrovirus (NPV), such as microscopic diagnosis (Traverner MP, Connor, 1992), serological techniques (Brown et al., 1982, Naser and Miltenburger, 1983, Webb and Shelton, 1990), radioimmunoassay techniques (Smith and Summers, 1981, Knell et al., 1983), and DNA dot blot hybridization assays (Ward et al., 1987, Keating et al., 1989). The use of these techniques has been limited because they are either tedious and unreliable, or because they utilize radioactive materials.

Polyhedrin is the major component of polyhedra and has often been studied. After the first report about localization of the polyhedrin gene in AcNPV (Vlak and Smith, 1982), Iddekinge et al. (1983) determined its nucleotide sequences. At the last count, there was published data on the complete genome sequence of some 41 or more NPVs. Polyhedrin is a protein of about 245 to 250 amino acids, and appears to be the most highly conserved NPV protein. These characteristics lead to the use of polyhedrin sequences as the base of NPV phylogenetic studies (Zanotto et al., 1993).

The polymerase chain reaction (PCR) is a highly sensitive technique, which amplifies target DNA sequences and does not employ radioactive material. PCR has been extensively used to detect many organisms such as animal, human, plant, and various pathogens. Webb et al. (1991) reported the use of PCR to screen baculovirus expression vector recombinants in cell cultures. Burand et al. (1992) was able to detect baculovirus DNA sequences from viral occlusion bodies contaminating the surface of gypsy moth eggs.

The aim of the present study was to design degenerate primer set to detect multiple NPVs using PCR technique. The ability to detect NPV polyhedrin will be a useful tool in studies seeking to rapidly elucidate a polyhedrin gene structure, to monitor the release of the wild type as well as genetically engineered NPVs, and to isolate NPVs in the natural environment.

\section{MATERIALS AND METHODS Polyhedrin sequence data}

All polyhedrin sequences of nucleopolyhedrovirus (NPV) available in March 2010 from GenBank, EMBL, and DDBJ were downloaded. 152 nucleotide sequences were aligned using ClustalX software. Neighbour joining tree was examined using ClustalX and no divergent sequences were identified. In addition, the alignment was manually corrected by shifting sequences in places, for some sequences possessed large spans of unique deletions or insertions which threw off the alignment algorithm.

\section{Selection of highly conserved genome regions for primer design}

The term "conserved genomic regions" used here is defined as genome regions that have most frequently presented nucleotide sequences. To identify the highly conserved regions eligible for primer design, pairwise scan for the sequences was done and base by base alignment output file was produced using Mega4 and/ or ClustalX softwares. The most frequently presented base in the same coordinate for all sequences of the alignment was detected. The output (FASTA file) was then analyzed by ClustalX software to select candidate conserved regions for primer design. A candidate region was defined as a site within the polyhedrin open reading frame (orf) that had $17+$ bases from the 
3' end and with a base frequency of $0.80+$. Candidate conserved regions were identified by calculating redundancy scores and the average dominant base counts. Average dominant base counts were calculated by summing the number of occurrences of the most common base at each position in a window length of 20 bases and averaging those counts across all positions in the window.

\section{Primer design}

The distance between conserved regions was taken into account when selecting conserved sites as was the potential for using mixed bases or deoxyinosines, to enhance bonding at variable positions. Standard nucleotides were preferred close to the 3 ' termini of the oligonucleotides. The different parameters of primer design (length and sequence, GC content, Tm,........etc.) were taken into consideration. One set of degenerate primers common for the whole group was designed. Primers were designed to amplify 355 bp within the polyhedrin gene. The accession numbers of polyhedrin nucleotide sequences used in this study are listed in Table (1).

Table 1: Nucleopolyhedroviruses and sources of sequence information for sequences used in the present study.

\begin{tabular}{|c|c|c|c|c|c|c|c|}
\hline EF418027 & AY706678 & AF068188 & AF 499687 & cie923762 & AYS 19234 & AY706717 & AY7066933 \\
\hline AY706856 & AY7066885 & DQ238113 & FI182057 & Ge923751 & AY706679 & AY706718 & A2277555 \\
\hline De231336 & EU698891 & M14885 & AY706703 & Ge923360 & $\mathrm{AB} 465491$ & AY442260 & X55658 \\
\hline De231339 & AY7066700 & AY7298808 & AY706702 & cie923738 & FF901339 & AY7067114 & AYS 19243 \\
\hline Ax779044 & AY519249 & EV201037 & AY706701 & Ge923377 & DQ344541 & $\mathrm{AF} 037262$ & AY706708 \\
\hline De0s92424 & AY7066882 & U91940 & AYS 192288 & cie923356 & M21887 & AY706715 & AY706704 \\
\hline U75359 & ACU40834 & AYS 192222 & AYS 19213 & cie923761 & M13056 & AY7067716 & AYS8S504 \\
\hline M30925 & AY7067700 & FII57293 & AF016916 & X94437 & Kol 149 & $A B 326102$ & AYS 10240 \\
\hline DD 483053 & AY7066884 & U67258 & AY706710 & cies32064 & $\mathrm{AF} 300872$ & AF068189 & AYS519237 \\
\hline$\times 63614$ & AYS19255 & U67257 & AY7066833 & AY7060707 & $\mathrm{AB} 465488 \mathrm{~B}$ & $A Y 549963$ & AYY126617 \\
\hline AYSI9216 & AF118850 & U67256 & Ge4753265 & U30302 & AY706712 & AY549964 & U61732 \\
\hline De399596 & AY7066991 & U67255 & AYSI 19204 & AB 338406 & AF093405 & AY552474 & FSS17140 \\
\hline AY706719 & AYS $19210^{\circ}$ & AF 157012 & Ge9237359 & AY706705 & EU401915 & EF585249 & \\
\hline AF 169480 & AYS 19228 & A25670 & J04333 & EVOA7914 & EU401917 & AY706688 & \\
\hline AY706720 & AF 232690 & U97657 & Ge923735 & AY706706 & EU401916 & AY706699 & \\
\hline Ax706687 & DQ014543 & FII57291 & Ge9233754 & AY706698 & AF019882 & AY706690 & \\
\hline ABBo2454 & DQ0144542 & FII 57295 & Ge9293753 & AY706696 & $A B 300344$ & AY7066992 & \\
\hline DQ231347 & AY971675 & FII57294 & Ge9293752 & AY706697 & DQ350142 & AYS 19219 & \\
\hline AY706711 & AY899150 & FII57292 & Geg93750 & AY706681 & Do1017 & AY706699 & \\
\hline AY706580 & M2433 & M23176 & Ge923749 & AY766713 & AY600451 & $\mathrm{DQ} 2313142$ & \\
\hline
\end{tabular}

\section{Viruses, cell lines and insects}

The nucleopolyheroviruses tested in this study were as follows: Autographa californica (AcMNPV), Bombyx mori NPV (BmNPV), Hyphantria cunea NPV (HcNPV), Lymantria dispar NPV (LdNPV), Spodoptera exigua NPV (SeNPV), S. litura NPV (SINPV), Spodoptera littoralis NPV (SpliNPV) and nine local NPV isolates. The AcMNPV, BmNPV and $H c \mathrm{NPV}$ were propagated in $S f 9$ cells maintained at $27^{\circ} \mathrm{C}$ in a TC- 100 medium (Gibco-BRL, USA) that was supplemented with $10 \%$ fetal bovine serum (Gibco-BRL, USA). The SeNPV, SINPV, SpliNPV, LdNPV and local isolates were propagated in S. littoralis and L. dispar larvae. Routine cell culture maintenance and virus production procedures were carried out according to O'Reilly et al. (1992). Insect colonization and maintenance of the cotton leafworm, Spodoptera littoralis, was done in the insectary of Department of Entomology, Faculty of Science, Cairo University under highly controlled conditions from 1995 to date. The colony was maintained in the laboratory according to Seufi (2008). These insects were used for viral propagation and purification assays.

\section{Virus DNA purification}

Virus DNA was extracted from purified, semipurified polyhedra collected from infected cells and insect larvae. Total genomic DNA was also extracted from insect larvae. The virus isolates were successfully propagated and purified following the method described by Lacey et al. (2002). To extract virus DNA, purified or semipurified polyhedra were resuspended in a $0.1 \mathrm{M}$ sodium carbonate solution (0.1 M Na2CO3, 0.17 $\mathrm{M} \mathrm{NaCl}, 0.01 \mathrm{M}$ EDTA, $\mathrm{pH}$ 10.9), and incubated at $37^{\circ} \mathrm{C}$ overnight with a final concentration of $0.5 \mathrm{mg} / \mathrm{ml}$ of proteinase K (Sigma, USA) and $1 \%$ of SDS. A further extraction with phenol 
and chloroform: isoamylalcohol (24:1) was performed and the DNA was ethanol-precipitated. The DNA was resuspended in a TE buffer $(10 \mathrm{mM}$ Tris-HCl, 1mM EDTA, pH 8.0).

\section{PCR amplification}

PCR amplification was performed according to Saiki et al. (1988) with minor modifications. Total DNA was extracted from the NPV isolates and the DNA segment was amplified using two primers designed based on conserved nucleotide sequences of 152 different polyhedrin sequences. Sequence of the forward and reverse primers used in this study, their length, GC content and base counts were shown in Table (3 and 4). Total reaction volume was $50 \mu \mathrm{l}$ which contained $1 \times$ PCR buffer (Promega), $1.5 \mathrm{mM} \mathrm{MgCl}$, $200 \mu \mathrm{M}$ dNTPs, 2.5 U Taq DNA polymerase (Promega), $100 \mathrm{ng}$ of each primer and $30 \mathrm{ng}$ of template DNA. The amplification program used was $3 \mathrm{~min}$ at $94^{\circ} \mathrm{C}$ (hot start), $1 \mathrm{~min}$ at $94^{\circ} \mathrm{C}, 2 \mathrm{~min}$ at $55^{\circ} \mathrm{C}$ and $2 \mathrm{~min}$ at $72^{\circ} \mathrm{C}$ for 35 cycles followed by one cycle of $72^{\circ} \mathrm{C}$ for $7 \mathrm{~min}$. PCR amplification was carried out in a DNA thermal cycler (Model 380 A, Applied Biosystems, CA, USA).

\section{RESULTS \\ Selection of Candidate Conserved Region for Primer Design}

Alignment of the 152 NPV polyhedrin sequences were used as a guide to enable identification of conserved sequences of the gene to be used in the design of degenerate oligonucleotide primers for PCR. No potentially useful conserved sites were identified in the first complete multiple alignment, utilizing all available sequences in GenBank, EMBL, and DDBJ databases. However, once divergent sequences were removed, eleven conserved regions were identified. Two candidate regions (from 154 to 172 and 465 to 505 relative to the Cotesia marginiventris NPV polyhedrin gene (Acc\# EF418027)) with relatively low levels of degeneracy were selected to design primers (Table 2).

Table 2: Number, length and location of the identified
conserved regions in the 152 polyhedrin gene
sequences used in this study. Locations were
determined in relation to the Cotesia marginiventris
NPV polyhedrin gene (Acc\# EF418027). The candidate
conserved regions were determined using pairwise and
multiple sequence alignments.

\begin{tabular}{|c|c|c|}
\hline Conserved region & Location & Length $(\mathrm{bP})$ \\
\hline 1 & $154-175^{*}$ & 22 \\
2 & $222-242$ & 21 \\
3 & $251-277$ & 27 \\
4 & $279-297$ & 19 \\
5 & $300-347$ & 48 \\
6 & $371-409$ & 39 \\
7 & $410-446$ & 37 \\
8 & $465-505^{*}$ & 41 \\
9 & $508-534$ & 27 \\
10 & $585-620$ & 36 \\
11 & $626-650$ & 25 \\
\hline
\end{tabular}

One set of degenerate PCR primers (Polh152F and Polh152R) was designed from these regions.

\section{Primer Selection}

The Polh152F and Polh152R primers were designed to amplify $355 \mathrm{bp}$ within the polyhedrin gene (based on 152 polyhedrin sequences). The sequences of The Polh152F and Polh152R primers and the base count of the respective viral DNAs are shown in Tables (3 and 4). Degenerate sites were considered when low base by base frequency was produced by multiple alignment in the candidate regions. The primers were selected on the basis of having relatively low levels of degeneracy. The bases represented in lower than $5 \%$ in the base count were not considered in designing the primers (Tables 3 and 4). To compensate for the primer multiplicity, a slightly higher primer concentration (50 pmole per 50 $\mu l$ reaction) was used in the PCR.

\section{Experimental verification}

Two degenerate primers were designed to anneal within the orf of polyhedrin gene (Polh152F and Polh152R). The degenerate PCR primer set successfully amplified the expected polyhedrin DNA fragment (355 bp) from the AcMNPV, BmNPV, HcNPV, $L d \mathrm{NPV}$, SeNPV, SINPV, SpliNPV as well as from nine local NPV isolates. 
Table 3: Sequence and base counts of the forward primer based on the first candidate conserved region of 152 polyhedrin sequences. Base count less than $5 \%$ was neglected in primer design.

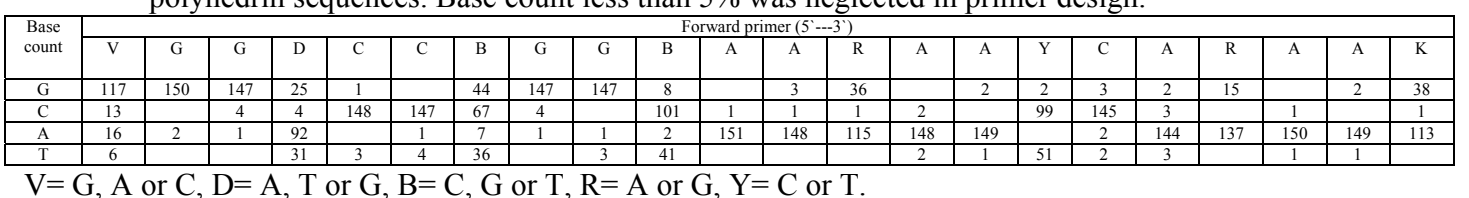

Table 4: Sequence and base counts of the reverse primer based on the eighth candidate conserved region of 152 polyhedrin sequences. Base count less than $5 \%$ was neglected in primer design.

\begin{tabular}{|c|c|c|c|c|c|c|c|c|c|c|c|c|c|c|c|c|c|c|c|c|c|c|}
\hline $\begin{array}{c}\text { Base } \\
\text { count }\end{array}$ & $\mathbf{C}$ & $\mathbf{A}$ & $\mathbf{D}$ & $\mathbf{C}$ & $\mathbf{C}$ & $\mathbf{R}$ & $\mathbf{Y}$ & $\mathbf{Y}$ & $\mathbf{R}$ & $\mathbf{Y}$ & $\mathbf{M}$ & $\mathbf{N}$ & $\mathbf{Y}$ & $\mathbf{K}$ & $\mathbf{Y}$ & $\mathbf{T}$ & $\mathbf{T}$ & $\mathbf{R}$ & $\mathbf{S}$ & $\mathbf{C}$ & $\mathbf{B}$ & $\mathbf{A}$ \\
\hline $\mathbf{G}$ & & 1 & 94 & 5 & 1 & 126 & 2 & 1 & 127 & & & 9 & 2 & 36 & & 1 & & 99 & 45 & 2 & 19 & 1 \\
\hline $\mathbf{C}$ & 148 & & & 144 & 151 & 1 & 140 & 141 & 2 & 125 & 124 & 65 & 37 & 1 & 77 & 1 & 3 & 4 & 100 & 140 & 105 & \\
\hline $\mathbf{A}$ & 2 & 151 & 42 & 1 & & 24 & 2 & 1 & 18 & 6 & 25 & 10 & 2 & & & & & 45 & 3 & 6 & 5 & 149 \\
\hline T & 2 & & 16 & 2 & & 1 & 8 & 9 & 5 & 21 & 3 & 68 & 111 & 115 & 75 & 150 & 149 & 4 & 4 & 4 & 23 & 2 \\
\hline
\end{tabular}

$\mathrm{D}=\mathrm{A}, \mathrm{T}$ or $\mathrm{G}, \mathrm{B}=\mathrm{C}, \mathrm{G}$ or $\mathrm{T}, \mathrm{R}=\mathrm{A}$ or $\mathrm{G}, \mathrm{Y}=\mathrm{C}$ or $\mathrm{T}, \mathrm{K}=\mathrm{G}$ or $\mathrm{T}, \mathrm{M}=\mathrm{C}$ or $\mathrm{A}, \mathrm{S}=\mathrm{C}$ or $\mathrm{G}, \mathrm{N}=\mathrm{A}, \mathrm{C}, \mathrm{T}$ or $\mathrm{G}$.

Non-specific amplification products were not observed for tested NPVs. In total all of the nine NPV species tested were amplified, seven species and two local isolates have been tested with these primers (Fig. 1). Three randomly chosen PCR products were cloned into $p$ GEM-T vector and sequenced. The sequencing results showed that the three PCR products were fragments of polyhedrin gene (data not shown).

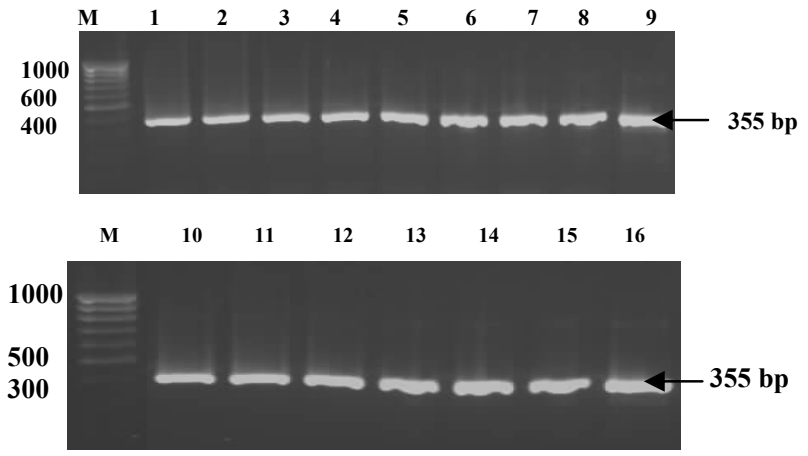

Fig. 1: Representative PCR results showing the amplification of $\sim 355 \mathrm{bp}$ fragment in the polyhedrin gene coding region of $16 \mathrm{NPV}$ isolates. M: 100 bp ladder DNA marker, lanes 1: AcMNPV, 2: SINPV, 3: SeNPV, 4: LdNPV, 5: HcNPV, 6: BmNPV and 7: SpliNPV. Lanes 8-16: nine NPV local isolates. The size of the bands is shown in bp.

\section{DISCUSSION AND CONCLUSION}

Polyhedrin gene of NPVs encodes for the matrix protein of the virus occlusion body and is one of the most conserved baculovirus genes (Jehle, 2004). This gene was proved to be the most suitable gene in baculoviruses for developing generic amplification technique (Woo, 2001). Seufi (2008) characterized a highly conserved polyhedrin region of $405 \mathrm{bp}$ molecular size. $\mathrm{He}$ reported that alignment results of this conserved region with the other published sequences produced significant alignment with 111 baculovirus isolates. The percentage of homology ranged between $99 \%$ for SpliNPV (Acc\# D01017) and 78\% for Plusia orichalcea NPV (Acc\# AF019882). At the level of amino acid sequence, the percentage homology of ranged between $100 \%$ for S. littoralis polyhedrins (Acc\# AAC33752 and AAR04375) and 81\% for Attacus ricini polyhedrin (Acc\# P31036). In addition, lepidopteran polyhedrin genes show about a 50\% amino acid identity with granulovirus granulins, and a 40\% identity with hymenopteran NPV polyhedrin (Rohrmann, 1992). These high similarities could enhance the strategy to design universal primers for rapid and early detection of NPV-infection. The advantage of such approach is that it utilized all NPV polyhedrin sequences available in the international databases (152 sequences) and simple public software programs to select optimal candidate regions in genomic sequences 
for amplification. Such approach is unlikely to produce significant bias towards any one species, especially when there is no bias in the multiple sequence alignment which the approach was based on. These primers make it possible to efficiently amplify DNA from many NPV species and allow further search for unknown NPV species.

Many published reports that investigated polyhedrin gene depended primarily on a Southern hybridization using probes of the polyhedrin gene of other previously identified viruses. However, this technique is efficient only if the similarity between polyhedrin genes of the target NPV and probe NPV is high. Therefore, many limitations will arise when the study based mainly on Southern technique. One major limitation is that this technique requires multiple probes of various NPVs for detection of baculovirus. Also, traditional serological methods based on neutralization and fixed cell ELISA have proven effective for identifying baculoviruses (Brown et al., 1982). However, difficulties in interpreting antigenic cross reactivity or failure to identify relatively close antigenic relationships were common complains in this technology. Moreover, serology is time consuming, requires highly experienced personnel and is less precise than nucleotide sequence determination.

Generally, the use of PCR technology for virus detection, identification and characterization is a basic tool in many virological laboratories (Moraes and Maruniak, 1997, Moraes et al., 1999, Murillo et al., 2006). Indeed, a good set of primers for nucleopolyhedrovirus detection is a powerful tool for large nucleopolyhedrovirus sample screening. PCR technique is preferred because it is easy, fast, sensitive and reliable. In addition, it does not utilize radioactive materials. Although attempts to detect nucleopolyhedroviruses from soil and insects have been made using PCR techniques, it was limited to narrow NPV species (Webb et al., 1991, Moraes and Maruniak, 1997, Moraes et al., 1999). Woo (2001) designed a pair of degenerate primers (based on conserved amino acid sequence of 26 different NPVs) to detect multiple NPVs using PCR. One major problem with degenerate primers is that the concentration of some permutations in the mixture is so small that amplification is effectively inhibited (due to their great multiplicity). It was believed that the redundancy of Polh152F and Polh152R was insufficient to cause this problem. The capacity of Polh152F and Polh152R primers potentially to amplify all NPVs made them an invaluable diagnostic and taxonomic tool for virology. The ability of these primers to amplify DNA from local isolates of NPV may demonstrate their capacity to define novel NPV species.

In conclusion, the PCR primer set employed in this study was chosen from highly conserved sequences within the polyhedrin-coding region. Therefore, the possibility of amplification of multiple nucleopolyhedroviruses was more enhanced. The present study introduced a highly sensitive method for multiple nucleopolyhedrovirus detection. Higher sensitivity and cost-efficiency enabled the researcher to identify the structure of the polyhedrin gene rapidly. The amplification of highly specific and abundant products obtained in this study suggests that this method might be useful to detect nucleopolyhedroviruses with low amounts of DNA in the environment. Conclusively, the method described in this paper is universal, powerful, and could be used in the future to study the environmental fate of wild type or genetically modified recombinant NPVs. It may be usefull in quality control studies of baculoviral insecticides as well. 


\section{REFERENCES}

Blissard, G.W. and Rohrmann, G.F. (1990): Baculovirus diversity and molecular biology. Annu. Rev. Entomol., 35:127-155.

Brown, D.A.; Allen, C.J. and Bignell, G.N. (1982): The use of a protein A

conjugate in an indirect enzyme-linked immunosorbent assay (ELISA) of four closely related baculoviruses from Spodoptera species. J. Gen. Virol., 62:375378.

Burand, J.P.; Horton, H.M.; Retnasami, S. and Elkington, J.S. (1992): The use of polymerase chain reaction and shortwave UV irradiation to detect baculovirus DNA on the surface of gypsy moth eggs. J. Virol. Methods, 36:141-150.

Choi, J.Y.; Woo, S.D.; Je, Y.H. and Kang, S.K. (1999): Development of a novel expression vector system using Spodoptera exigua nucleopolyhedrovirus. Mol. Cells, 9:504509.

Christian, P.D.; Gibb, N.; Kasprzak, A.B. and Richards, A. (2001): A rapid method for the identification and differentiation of Helicoverpa nucleopolyhedroviruses (NPV Baculoviridae) isolated from the environment. J. Virol. Methods, 96:51-65.

Herniou, E.A.; Olszewski, J.A.; O'Reilly, D.R. and Cory, J.S. (2004): Ancient coevolution of baculoviruses and their insect hosts. $J$. Virol., 9: 3244-3251

Iddekinge, B.J.; Smith, G.E. and Summers, M.D. (1980): Nucleotide sequence of the polyhedrin gene of Autographa californica nuclear polyhedrosis virus. Virol., 131:55615565.

International Committee on Taxonomy of Viruses (2009): Virus Taxonomy: 2009 Release.

Jehle, J.A. (2004): The Mosaic Structure of the Polyhedrin Gene of the Autographa californica Nucleopolyhedrovirus (AcMNPV). Virus Genes, 29 (1):5-8.

Jehle, J.A.; Lange, M.; Wang, H.; Zhihong, H.; Wang, Y. and Hauschild, R. (2006): Molecular identification and phylogenetic analysis of baculoviruses from Lepidoptera. Virol., 346:180 - 193.

Keating, S.T.; Burand, J.P. and Elkington, J.S. (1989): DNA hybridization assay for detection of gypsy moth nuclear polyhedrosis virus in infected gypsy moth (Lymantria dispar L.) larvae. Appl. Environ. Microbiol., 55:2749-2754.

Knell, J.D.; Summers, M.D. and Smith, G.E. (1983): Serological analysis of 17 baculoviruses from subgroup A and B using protein blot immunoassay. Virol., 125:381392.
Lacey, L.A.; Vail, P.V. and Hoffmann, D.F. (2002): Comparative activity of baculoviruses against the codling moth Cydia pomonella and three other tortricid pests of tree fruit. J. Invertebr. Pathol., 80:64-68.

Lange, M.; Wang, H.; Zhihong, H. and Jehle, J.A. (2004): Towards a molecular identification and classification system of lepidopteran-specific baculoviruses. Virol., 325:36-47.

Leung, K.; England, L.S.; Cassidy, M.B.; Trevors, J.T. and Weir, S. (1994): Microbial diversity in soil: effect of releasing genetically engineered microorganisms. Mol. Ecol., 3:413-422.

Marks, H.; Ren, X.; Witteveldt, J.; Sandbrink, H.; Vlak, J.M. and van Hulten, M.C. (2005): Transcription regulation and genomics of White Spot Syndrome Virus. In Diseases in Asian Aquaculture $V$ Edited by: Walker $\mathrm{P}$, Lester R, Bondad-Reantaso MG. Fish Health Section, Asian Fisheries Society, Manila, pp:363-377.

Moraes, R.R.; Maruniak, J.E. and Funderburk, J.E. (1999): Methods for detection of Anticarsia gemmatalis nucleopolyhedrovirus DNA in soil. Appl. Environ. Microbiol., 65:2307-2311.

Moraes, R.R. and Maruniak, J.E. (2001): Detection and identification of multiple baculoviruses using the polymerase chain reaction (PCR) and restriction endonuclease analysis. Mol. Cells, 11:334-40.

Moraes, R.R. and Maruniak, J.E. (1997): Detection and identification of multiple baculoviruses using the polymerase chain reaction (PCR) and restriction endonuclease analysis. J. Virol. Methods, 63:209-217.

Murillo, R.; Munoz, D.; Williams, T.; Mugeta, N. and Caballero, P. (2006): Application of the PCR-RFLP method for the rapid differentiation of Spodoptera exigua nucleopolyhedrovirus genotypes. J. Virol. Methods, 135:1-8.

Murphy, F.A.; Fauquet, C.M.; Bishop, D.H.; Ghabrial, S.A.; Jarvis, A.W.; Martinelli, G.P.; Mayo, M.A. and Summers, M.D. (1995): Virus Taxonomy. Springer Verlag, Vienna.

Naser, W.L. and Miltenburger, H.G. (1983): Rapid baculovirus detection, identification, and serological classification by western blotting-ELISA using a monoclonal antibody. J. Gen. Virol., 64:639-647.

O'Reilly, D.R.; Miller, L.K. and Luckow. V.A. (1992): Baculovirus expression vectors: a laboratory manual. Freeman, New York, USA. 
Rohrmann, G.F. (1992): Baculovirus structure proteins. J. Gen. Virol., 73:749-761.

Saiki, R.K.; Gelfand, D.H.; Stoffel, S.; Scharf, S.J.; Higuchi, R.; Horn, G.T.; Mullis, K.B. and Erlich, H.A. (1988): Primer-directed enzymatic amplification of DNA with a thermostable DNA polymerase. Science, 239:487-491.

Seufi, A.M. (2008): Characterization of an Egyptian Spodoptera littoralis nucleopolyhedrovirus and a possible use of a highly conserved region from polyhedrin gene for nucleopolyhedrovirus detection. Virol. J., 5:13.

Smith, G.E. and Summers, M.D. (1981): Application of a novel radioimmunoassay to identify baculovirus structural proteins that share interspecies antigenic determinants. $J$. Virol., 39:125-137.

Summers, M.D. and Smith, G.E. (1987): A method for baculovirus vector and insect cell culture procedures, Texas Agricultural Experiment Station, Bulletin No. 1555.

Traverner, M.P. and Connor, E.F. (1992): Optical enumeration technique for detection of baculoviruses in the environment. Environ. Entomol., 21:307-313.

Vlak, J.M. and Smith, G.E. (1982): Orientation of the genome of Autographa californica nuclear polyhedrosis virus: a proposal. $J$. Virol., 41:1118-1121.

Wang, C.H.; Yang, H.N.; Liu, H.C.; Kou, G.H. and Lo, C.F. (2000): Nested polymerase chain reaction and in situ hybridization for detection of nucleopolyhedrosis. J. Virol. Methods, 84:65-75.

Ward, V.K.; Fleming, S.B. and Kalmakoff, J. (1987): Comparison of a DNA-DNA dotblot hybridization assay with light microscope and radioimmunoassay for the detection of a nuclear polyhedrosis virus. $J$. Virol. Methods, 15:65-73.

Webb, A.C.; Bradley, M.K.; Phelan, S.A.; Wu, J.Q. and Gehrke, L. (1991): Use of the polymerase chain reaction for screening and evaluation of recombinant baculovirus clones. Biotechniques, 4:512-519.

Webb, S.E. and Shelton, A.M. (1990): Effect of age structure on the outcome of viral epizootics in field populations of imported cabbageworm (Lepidoptera: Pieridae). Environ. Entomol., 19:111-116.

Woo, S.D. (2001): Rapid detection of multiple nucleopolyhedroviruses using polymerase chain reaction. Mol. Cells, 11:334-40.

Wood, H.A. and Robert, R.G. (1991): Genetically engineered baculoviruses as agents for pest control. Аnnu. Rev. Microbiol., 45:69-87.

Zanotto, P.M.; Kessing, B.D. and Maruniak, J.E. (1993): Phylogenetic interrelationships among baculoviruses: evolutionary rates and host associations. J. Invertebr. Pathol., 62:147-164.

\footnotetext{
ARABIC SUMMARY

تصميم زوج من البادئات العالمية للكثف المبكر والسريع عن أنواع متعددة من الباكيولوفيروسات باستخدام تفاعل البلمرة المتسلسل عن أنواعل

فاطمة حسين جلال

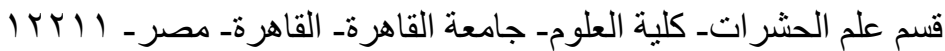

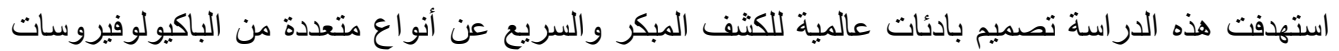

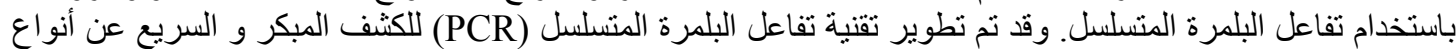

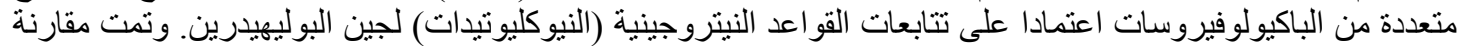

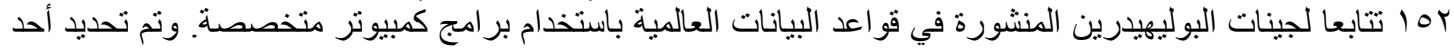

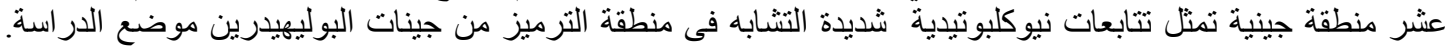

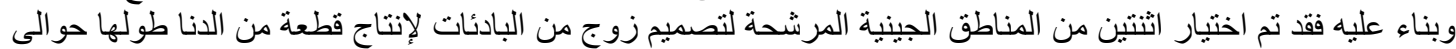

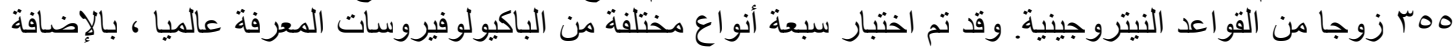

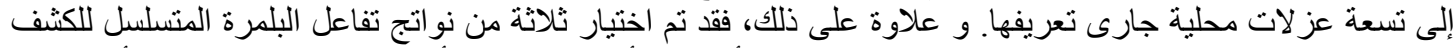

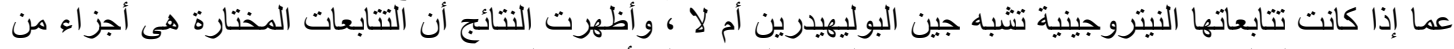

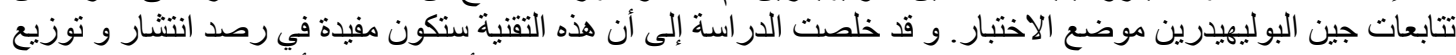

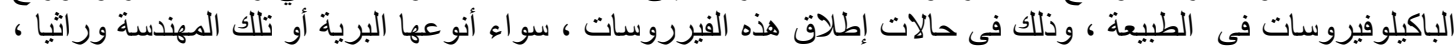
كما يكن الاستفادة منها فى اختبار ات الجودة وذئل للمبيدات الحيوية الفيروسة.
} 
